Joint seminar report

ED VAN HOVEN \title{
Transformation Processes
}

Transformation Processes and Islam in Africa was the theme of a conference held on 15 October 1999 at the African Studies Centre (ASC) in Leiden, the Netherlands. The conference was co-sponsored ISIM.

The conference addressed the various ways in which Islam is making its presence felt, not only in the regions of the continent which for centuries have belonged to Islam's sphere of influence, but also those that until recently have remained virtually untouched by Islam. Dutch research on Islam, having traditionally focused on Indonesia and the Middle East, testifies to the renewed interest in sub-Saharan Africa, a field which is rapidly gaining importance at the international level. These issues, as well as the role Islam plays as a vehicle of economic, political and ideological reorientation in many African societies, connecting them to broader society and appealing to more universal ideas and values, were discussed by Professor Wim van Binsbergen (Philosophy Faculty, Erasmus University Rotterdam) in his opening speech.

Professor Muhammed Khalid Masud, Academic Director of the ISIM, discussed the notion of transformation in Islam as a complex phenomenon of a public and sacred nature.
Professor Louis Brenner (keynote speaker) from the School of Oriental and African Studies (SOAS, London), elaborated on the kind of transformation represented in the case of the volunteer association, the model of Muslim socio-political organization in contemporary Mali. One of the questions raised by Professor Brenner was whether the epistemic shift from esoteriscism to rationalism, to which his welldocumented paper testified, is in fact a product of the increasing influence of Islam or consequence of the conflicting social and political forces of the societies to which Muslims belong. The second keynote speaker was Professor Lamin Sanneh from Yale University (USA), who raised the issue of mobility and liminality, physical as well as symbolic, in the processes of transformation and the contested identities they generate. Drawing on the work of Van Gennep and Victor Turner, and the latter's notion of communitas in particular, Sanneh isolated various types of marginaity of which 'prescriptive marginality' exemplified in the hijra is particularly relevant for the understanding of Muslim movements in sub-Saharan Africa.

Travelling from the west to the east of Afri$\mathrm{ca}$, the various contributions to the confer- ence brought to light the multifaceted manifestations of Islam and Islamic identities on the African continent. Marloes Janson (CNWS, eiden University) discussed the attempts of the female bards, who colour the streets of many Gambian towns, to legitimize their of ten-contested profession in terms of an Islamic discourse. Kirsten Langeveld (University of Utrecht) argued that in the neighbouring Casamance region (Senegal), the Jola Kumpo mask performance is under severe attack by Muslims though it still remains a (supernatural) force with which to be reckoned. Ed van Hoven (CNWS, Leiden University) examined the various attempts to 'muridize' Senegal's national culture, and the efforts of the state to mould political affiliation in terms of the sheikh/murid relationship.

The role of Islam and the motivation to travel of the Fulbe pastoralists living in Centra Mali was discussed by Mirjam de Bruijn (Leiden, African Studies Centre), while Frauke Jäger (Berlin, Germany) analysed the adaptation of Islam to specific socio-religious contexts with examples from Northern Nigeria and Northern Cameroon. The role ethnicity plays in the process of conversion to Islam in the North West Province of Cameroon was discussed in the combined presentation of Caroline Angenent (Leiden, LISOR) and Anneke Breedveld (African Studies Centre, Leiden). That Islam in this region is receiving new impulses with the Islamic movements opting for purification with far-reaching consequences for the moral discourse on gender relations, was argued by José van Santen (Department of Anthropology, Leiden University). Karin Willemse (Department of Non-Western History, Erasmus University Rotterdam) discussed the phenomenon of Islamism in the case of West Sudan and showed that Islamic discourses on gender entail both femininity and masculinity.

Further south, in Tanzania, Marc de Meij (IIMO) analysed the Muslims' attitudes towards the pluralistic state and the role of Swahili as a religious language. Wim van Binsbergen closed the conference with a well-documented analysis of the role of Islam as a constitutive factor in so-called African traditional religion.

Dr Ed van Hoven is a post-doctoral researcher at the School of Asian, African, and Amerindian Studies, University of Leiden, the Netherlands.

E-mail:e.vanhoven@inter.nl.net 